\title{
Herramienta educativa para facilitar el estudio de instalaciones eléctricas
}

\author{
Tania Catalina Amaya Rincón* \\ Francy Mayoli Casallas Caicedo** \\ Flavio Humberto Fernández Moral
}

Artículo recibido: 20-09-2008 y aprobado: 27-10-2009

Educational tool to facilitate the study of electrical installations

Resumen: Este trabajo describe una herramienta educativa para facilitar el estudio del área de Instalaciones Eléctricas; la herramienta consta de dos partes, la primera corresponde a un Material Educativo Computarizado que contiene toda la temática del área, con la que se espera que cada usuario se apropie del conocimiento a partir de la información que se brinda. La segunda corresponde a la plataforma que facilita el monitoreo y la administración del proceso enseñanza-aprendizaje por parte del docente. Una vez desarrollada la herramienta se realizaron las pruebas piloto y de campo con expertos en la materia y estudiantes. Estas pruebas permitieron verificar el correcto funcionamiento de la herramienta y realizar las modificaciones requeridas.

Palabras clave: Tecnologías de la información y comunicación, didáctica, enseñanza, aprendizaje, herramienta educativa. MEC.
Abstract: This paper describes an educational tool to facilitate the study of the area of electrical installations. This tool consists of two main parts: The first one is a Computerized Educational Material (CEM) that contains all the thematic area, which is expected that each user take control from the information provided. The second one corresponds to the platform which facilitates the monitoring and administration of the teaching-learning process by the teacher. Once developed the tool, a pilot and field tests were conducted under the control of experts and students. These tests allowed verifying the proper functioning of the tool and making the changes required.

Key words: Information technologies and communication, didacTIC, teaching, learning, educational tool.

\footnotetext{
Universidad Pedagógica y Tecnológica de Colombia, Facultad Seccional.

Correo electrónico: tatisamaya@yahoo.es

** Universidad Pedagógica y Tecnológica de Colombia. Correo electrónico: francymay.c@hotmail.com
} 


\section{Introducción}

La meta principal de la educación es proporcionar una formación básica e integral, coherente con las necesidades y los retos de una sociedad en permanente evolución (Lamadrid, 1999; Alanís, 2000); uno de los rasgos que caracterizarán a las sociedades del siglo XXI, es la incorporación plena de las Tecnologías de la Información y Comunicación (TIC) al campo profesional y personal (López y Morcillo, 2007).

A comienzos de los años 90 Las TIC desataron una explosión sin precedentes en las formas de comunicación, a partir de ahí, la internet pasó de ser un instrumento especializado de la comunidad científica a ser una red de fácil uso y acceso que modificó las pautas de interacción social ( Lara, et al., 2007). El uso de tecnologías en el aula de clase, abre la posibilidad de realización de nuevas herramientas tendientes a mejorar el proceso enseñanza-aprendizaje; en este caso, el computador no es el que debe proveer la estructura de conocimiento para el proceso de aprendizaje, sino que el docente es quien debe hacerlo.

El sistema educativo involucra principalmente dos agentes: el Educando y el Educador; estos elementos deben estar relacionados entre sí, teniendo como objetivo verificar los procesos y organizar la aprehensión y aplicación de los conocimientos (Bonza, et al., 2008). En consecuencia, la educación de hoy se encuentra enfrentada a una reorganización, evidente en el deseo de cambio e innovación, por esta razón la actividad educativa necesita de herramientas que permitan métodos y formas flexibles para la comprensión de los conocimientos y nuevos instrumentos para afianzar los saberes adquiridos.
Las TIC, entendidas como el conjunto de herramientas de software, redes de comunicación, computadores, bases de datos y todos aquellos dispositivos que permiten almacenar procesar y transferir información, presentan un enorme potencial para el desarrollo de material didáctico que utilice las ventajas que ofrecen este tipo de tecnologías. Dentro de estas posibilidades, los Materiales Educativos Computarizados (MEC) son una alternativa interesante ya que integran textos, imágenes, sonidos y videos en una estructura adecuada para la enseñanza de diversas temáticas.

El estudio de temas científicos y tecnológicos tiene cierto grado de dificultad pues en muchas ocasiones se deben considerar conceptos abstractos que son difíciles de ilustrar con los materiales didácticos tradicionales. Un ejemplo de ello es el concepto de campo electromagnético y los efectos que éste tiene en un conductor que se mueve dentro de él (González, et al., 2003).

Por este motivo, en el presente trabajo se plantea el desarrollo de una herramienta educativa para la enseñanza de las instalaciones eléctricas, que está formada por un Material Educativo Compuratizado (MEC) y una plataforma de administración. El MEC permite al estudiante indagar un conjunto de actividades que lo llevarán a un mejor aprendizaje; mientras que la plataforma permite al docente monitorear y administrar el proceso enseñanza-aprendizaje de sus educandos. Esta herramienta surge como respuesta a las necesidades expresadas por docentes y estudiantes del programa de Licenciatura en Educación Industrial de la Universidad Pedagógica y Tecnológica de Colombia, seccional Duitama. 
A continuación se hace una breve descripción de la estructura de la herramienta, de algunas de sus interfaces de usuario, los conceptos aplicados en su diseño, además de las pruebas realizadas y sus principales resultados.

\section{Materiales y métodos}

\section{Marco teórico}

Las Nuevas Tecnologías de la Información y Comunicación (NTIC) son herramientas computacionales e informáticas que procesan, almacenan, sintetizan, recuperan y presentan información para todo tipo de aplicaciones educativas, es decir, las TIC son medios y no fines (Lara et al. 2007). El uso de las computadoras en educación se ha caracterizado por una visión que las considera como herramientas puestas a disposición de los alumnos, que cumplen con el rol de facilitadoras para la indagación y la adquisición de conocimiento en ambientes de aprendizaje colaborativos e interactivos (De Corte, 1996; Koschmann, 1996).

Pensar la computadora como una "colaboradora" del estudiante o como una metáfora acuñada a esos efectos, 'herramienta cognitiva', implica considerarla como instrumento que puede asistir a los alumnos en la ejecución de tareas cognitivas cumpliendo ciertas funciones como: apoyar procesos cognitivos y metacognitivos, compartir la carga cognitiva proveyendo soporte a los estudiantes o permitir que ellos se comprometan en actividades que de otra forma, estarían fuera de su alcance (Lajoie, 1993). La computadora pasa a ser un instrumento que, en mayor o menor medida, puede habilitar la realización de ciertas actividades, obstaculizar la concreción de otras y, en conjunto, llegar a reconfigurar el entorno educativo del cual forma parte (Martínez et al., 2005)

Las TIC han permitido la globalidad en el mundo de la comunicación, facilitando la interconexión entre las personas e instituciones a nivel mundial y eliminando barreras espaciales y temporales. (Rosario, 2006). Las TIC, han generado una nueva forma de aprendizaje que implica ser un receptor-participante-activo de conocimientos, que aprende con la ayuda de expertos y compañeros dentro de un entorno que no tiene fronteras geográficas ni de horarios.

Para Galvis (1994) Material Educativo Computarizado (MEC), es un ambiente informático que permite al usuario, para el que fue preparado el material, vivir el tipo de experiencias educativas que se consideran deseables frente a una necesidad dada. Los MEC se caracterizan porque el alumno es quien controla su ritmo de aprendizaje, la cantidad de ejercicios que desea hacer, así como el número de veces que desea interactuar, además, decide cuando abandonar o reiniciar la aplicación, toda esta flexibilidad resulta ventajosa para el usuario.

\section{Diseño propuesto}

En la figura 1 se observa la estructura de la herramienta educativa, que está conformada por un MEC para la enseñanza de instalaciones eléctricas y una plataforma para la administración del aprendizaje; estos dos elementos se conjugan para brindar un apoyo adecuado, tanto a estudiantes como a docentes, en el desarrollo de la asignatura. El MEC contiene las temáticas a estudiar, donde se manejan los conceptos mediante ejemplos, imágenes, videos y audio que hacen de éste un material interactivo 
que atrae la atención del estudiante. La plataforma es de gran ayuda al docente y permite crear grupos de trabajo, foros, consultas y un reporte de actividades. Estos dos elementos se integran a través de la evaluación, que tiene como objetivo hacer el seguimiento del proceso enseñanza-aprendizaje.

Herramienta Educativa

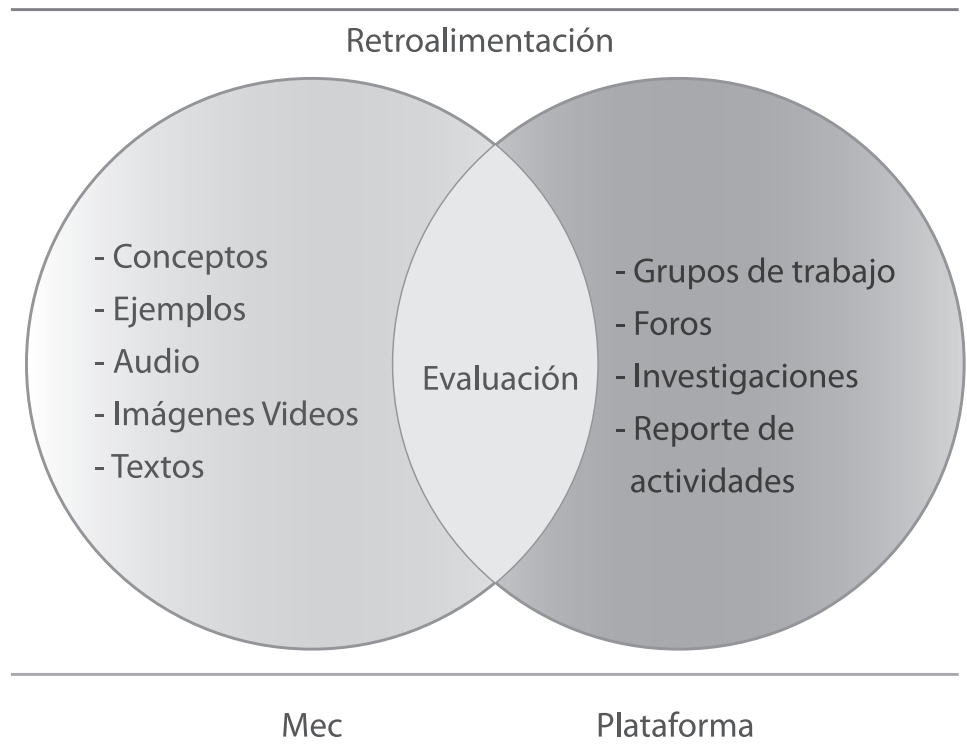

Figura 1. Estructura esquemática de la herramienta propuesta.

Para el desarrollo de la plataforma se utilizó el sistema Moodle (http:// es.wikipedia.org/wiki/moodle), que es útil para crear ambientes virtuales de estudio en línea y cuenta con herramientas como bases de datos de los usuarios, que permiten al profesor ver cuántas veces ha ingresado un estudiante, a qué hora y las estadísticas de sus evaluaciones, para luego hacer una retroalimentación de su proceso.

El MEC se desarrolló usando el lenguaje de programación Visual Basic 6.0, que permite crear ambientes multimedia que facilitan el aprendizaje, siguiendo la metodología propuesta por Galvis Panqueva (Galvis, 1994) para selección o desarrollo de materiales educativos computarizados que consta de las siguientes etapas:

- Análisis de la necesidad educativa. Con el fin de identificar el problema, se trabajó con un grupo de estudiantes y docentes del área de instalaciones eléctricas, además se consultaron diferentes fuentes de información en torno al tema, estableciendo la necesidad de contar con una herramienta que facilite el proceso enseñanza-aprendizaje de las instalaciones eléctricas. 
. Diseño. Esta fase se desarrolló teniendo en cuenta la creación de entornos atractivos para los usuarios con base en criterios como el diseño (educativo, de comunicación y computacional) soportado en factores como las funciones que debe cumplir la herramienta, la población objetivo, el contenido temático y las actividades a desarrollar, entre otros.

- Desarrollo. La herramienta se desarrolló bajo dos programas, El MEC, en Visual Basic y la plataforma de administración en Moodle. Una vez que el material estuvo disponible se realizaron las pruebas piloto y de campo cuyos resultados permitieron la puesta a punto de la herramienta.

\section{Estructura temática}

La temática tratada en el MEC corresponde a la asignatura de instalaciones eléctricas se organizan a partir del Reglamento Técnico de Instalaciones Eléctricas (RETIE) y la Norma NTC 2050, así como de las necesidades y sugerencias de docentes y estudiantes, quienes plantean las siguientes temáticas: generalidades sobre suministro eléctrico, simbología eléctrica, elementos que componen una instalación eléctrica, elaboración de montajes eléctricos, riesgos eléctricos, esquemas y planos eléctricos, tablas usadas en el cálculo de diseño de instalaciones, instalaciones industriales.

La información se encuentra estructurada de lo general a lo particular en cuatro niveles, a través de los cuales el estudiante puede navegar a voluntad, en la figura 2 se muestra la estructura del MEC, indicando las diez opciones principales que conforman el primer nivel, al igual que el contenido del segundo nivel para cada una de ellas.

\section{Estructura de la plataforma}

En la figura 3 se observa la estructura de la plataforma de administración, que tiene tres tipos de usuarios: profesor, administrador y estudiante; cada uno de ellos con su respectiva clave de acceso. La plataforma es de gran ayuda al docente ya que permite monitorear y administrar el proceso enseñanzaaprendizaje por medio de la creación de grupos, foros, consultas y evaluaciones, entre otras.

\section{Resultados y discusión}

\section{Material educativo computarizado}

Un MEC debe ser ameno, de fácil acceso, lleno de animación y colorido, con la información estructurada de tal manera que motive al estudiante a profundizar en la construcción de su propio conocimiento (Gómez et al., 2006), por esta razón, en la aplicación aquí descrita se realiza la navegación a través de menús como se muestra en la figura 4, donde el aprendiz puede escoger la opción que desea estudiar y así profundizar en el tema. 


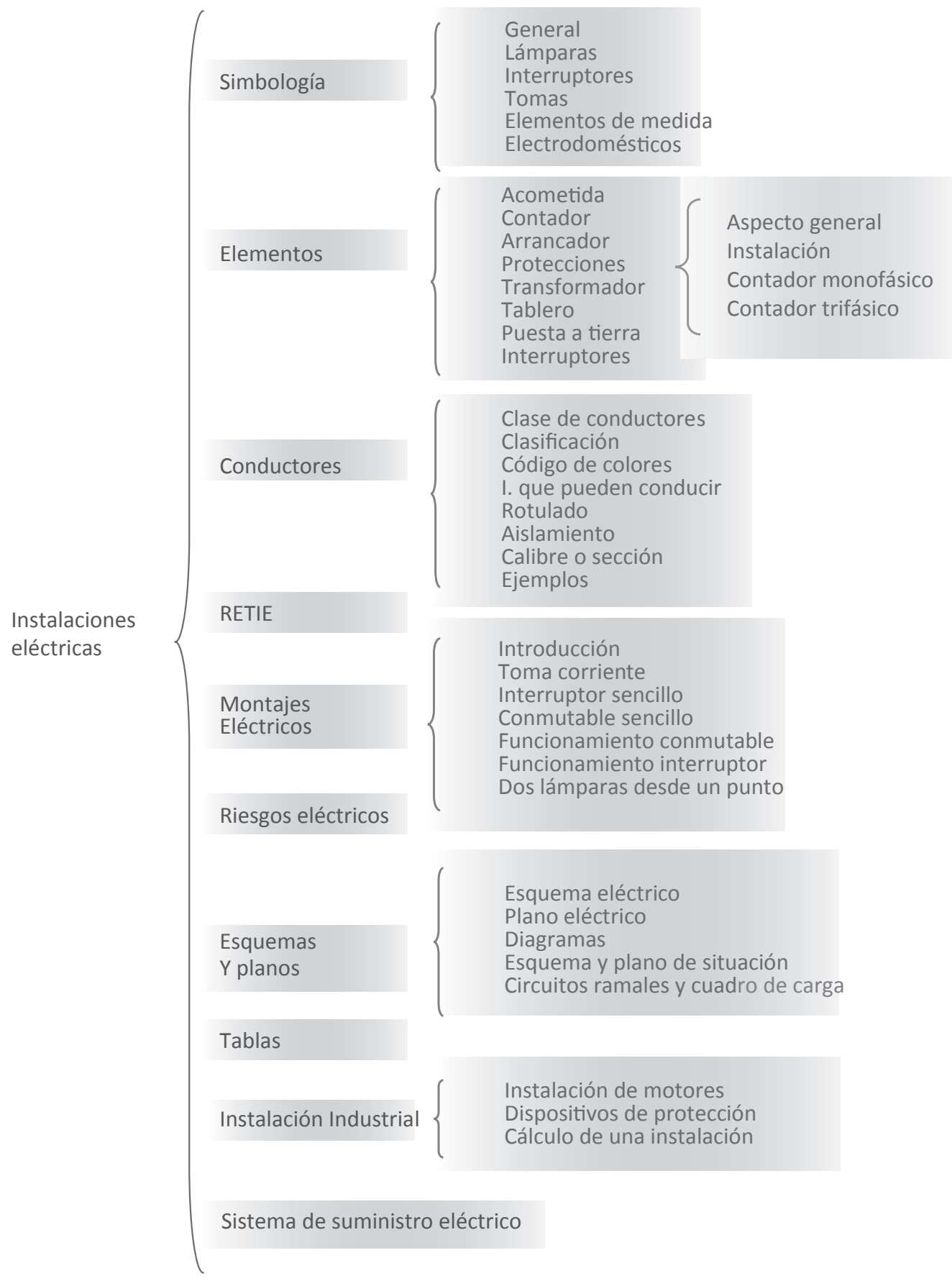

Figura 2. Estructura temática del MEC. 


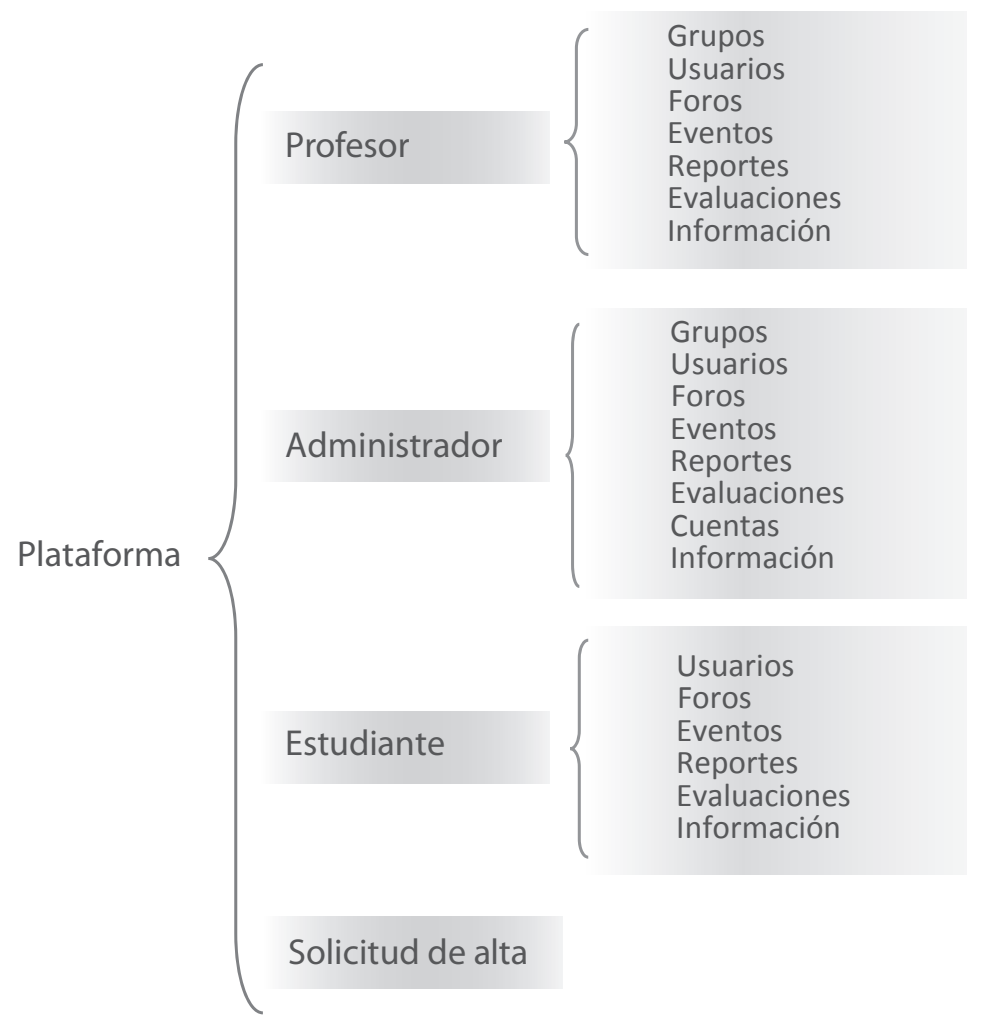

Figura 3. Estructura de la plataforma de administración.

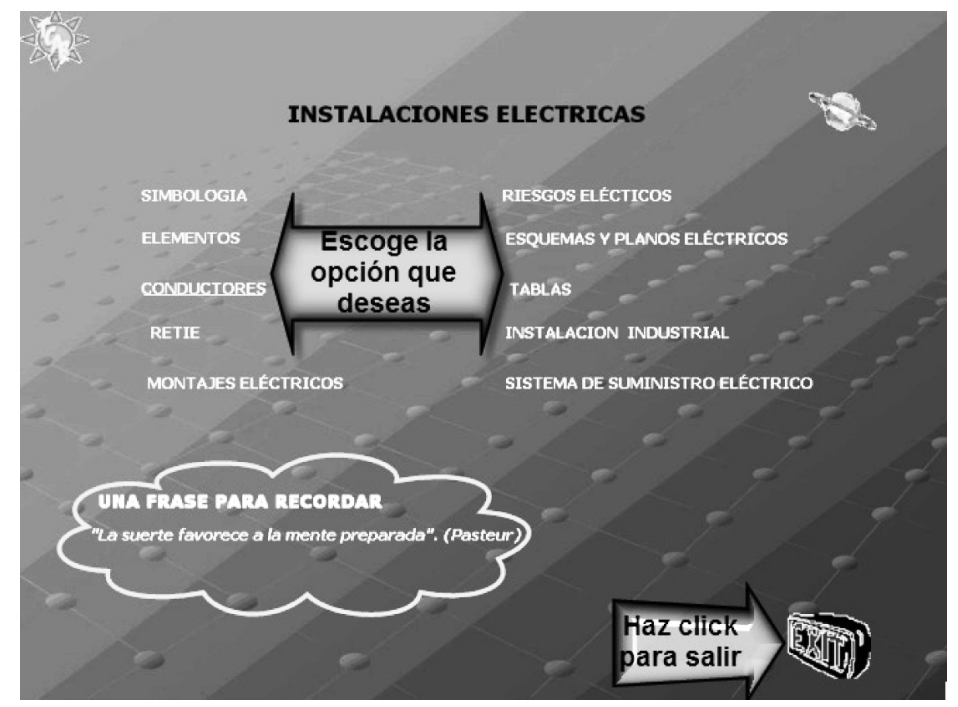

Figura 4. Pantalla Menú principal. 
La pantalla del menú principal (figura 4) contiene opciones que permiten interactuar con el MEC. Desplazándose por las opciones del menú principal se observan frases de personajes celebres, que invitan al estudiante a reflexionar sobre la vida para generar en ellos un cambio de actitud.
Se implementaron varias formas de presentar la información, una de ellas es por medio de imágenes como se observa en la figura 5, esta pantalla nos muestra como es el Sistema de suministro de electricidad por medio de una imagen y audio. Si el estudiante elige las palabra que se encuentra subrayada y de otro color, obtendrá como respuesta el concepto correspondiente en forma verbal.

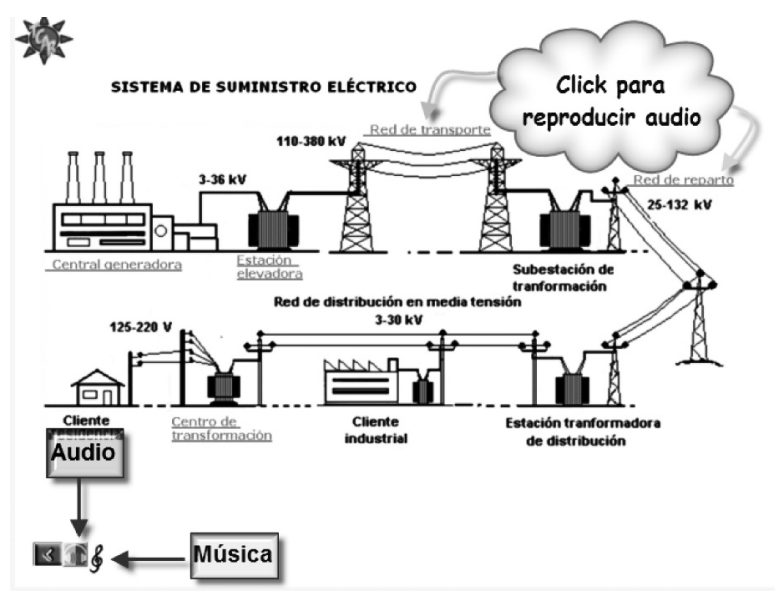

Figura 5. Pantalla Sistema de suministro eléctrico.

Otra forma de presentar la información es dando el concepto y toda la información necesaria para la construcción del conocimiento, por ejemplo en la figura 6 , se muestra el concepto y la tabla correspondiente para realizar los cálculos que permiten determinar la capacidad de corriente que puede soportar un conductor en una aplicación determinada.

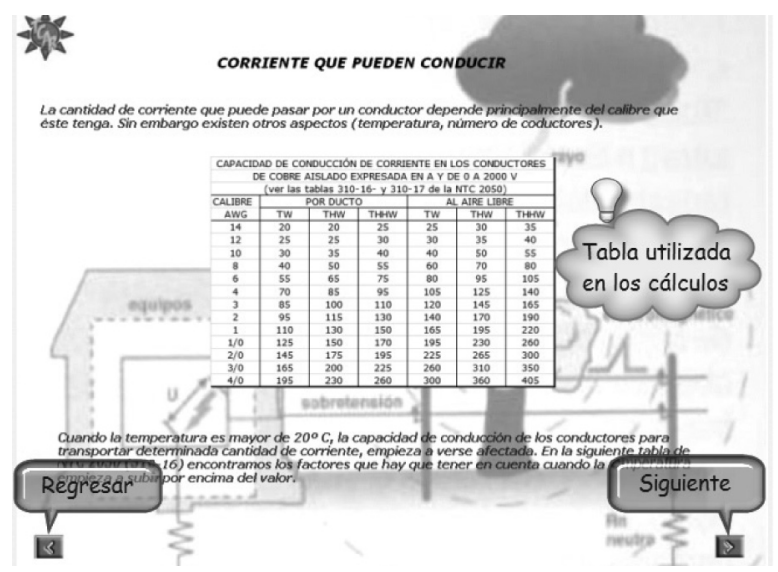

Figura 6. Pantalla Corriente que pueden conducir. 
Una vez se ha realizado la conceptualización del tema, se procede a estudiar un problema práctico y la solución respectiva, tal y como se ilustra en la figura
7, donde se pregunta acerca del calibre que deben tener ciertos conductores y a continuación se plantean los cálculos a realizar para determinar la solución.

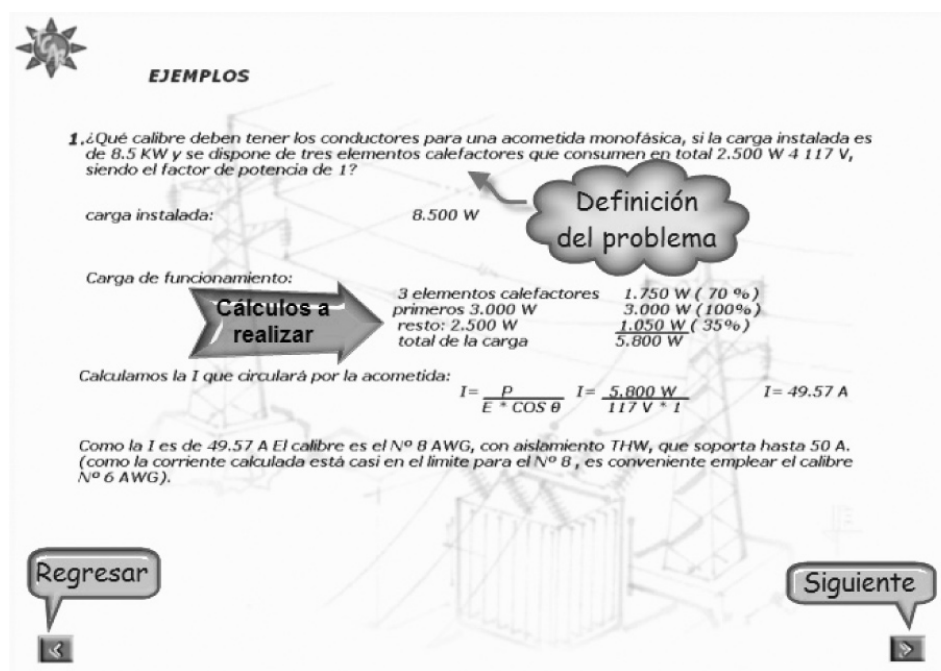

Figura 7. Ejemplo de cálculo de la corriente que soporta un conductor.

Además de estas opciones, la herramienta brinda la oportunidad al estudiante de observar, por medio de videos, cómo se realiza un montaje eléctrico, este procedimiento fortalece la apropiación de conceptos y facilita la apropiación de procedimientos mediante la exposición de situaciones reales propias de la temática; como ejemplo, se tiene el montaje y conexión de un interruptor conmutable. Los fondos que se utilizaron están relacionados con la asignatura (transformadores, arrancadores, conductores, protecciones, etc.), se manejan dos tamaños de letras y tres colores, con esto se busca crear una pantalla agradable y que no canse al estudiante.

Además de presentar la información al estudiante de una forma ordenada, se incorpora la opción de audio, la cual verbaliza el texto que aparece en pantalla y se activa a voluntad. Igualmente se ha incluido música de fondo que el estudiante decide si activa o desactiva como se observa en la figura 5.

\section{Plataforma}

De acuerdo con las funciones que trae Moodle la plataforma tiene tres módulos:

. Módulo del profesor: En el cual se puede realizar actividades como: creación de grupo, monitoreo a usuarios, realización de foros, adición de eventos, reporte de actividades y desarrollo de evaluación. Los elementos antes descritos se muestran en la figura 8.

. Módulo del estudiante: tiene como objetivo fomentar el desarrollo en el estudiante de actividades como ver 
los usuarios que se encuentran en la plataforma, desarrollar las evaluaciones, participar en los foros y proponer temas para los mismos, intercambiar información con los demás usuarios y desarrollar los trabajos y tareas. Los elementos antes descritos se muestran en la figura 9.

. Módulo del administrador: Este módulo permite realizar las mismas actividades previstas para el docente y al tiempo permite la opción de crear y borrar cuentas de usuario.

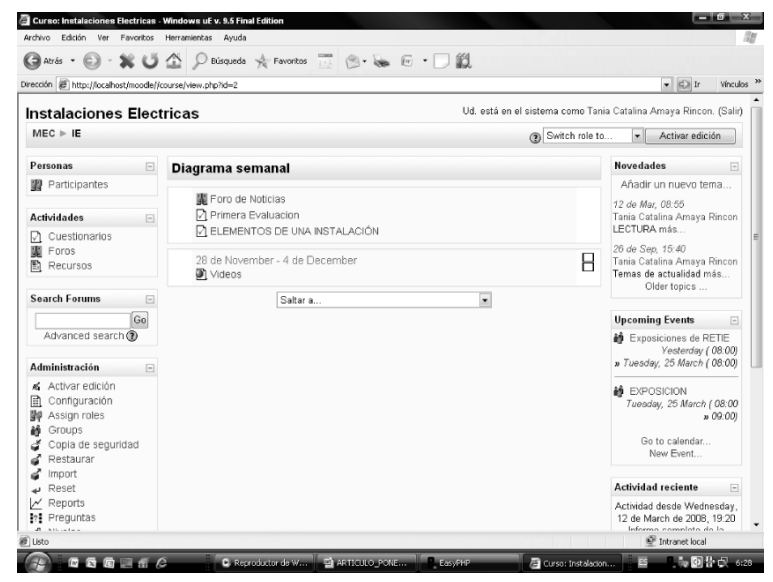

Figura 8. Módulo principal del profesor.

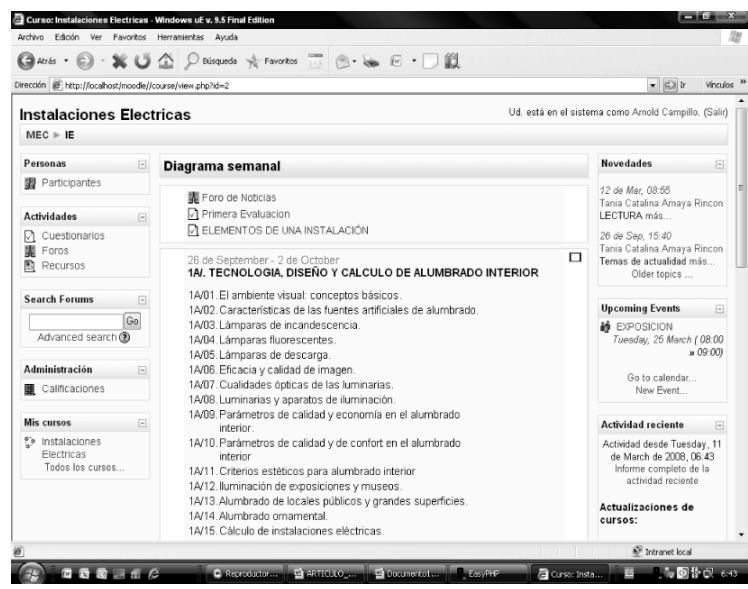

Figura 9. Módulo principal del estudiante.

\section{Pruebas realizadas}

Se aplicaron dos pruebas a la herramienta educativa, diseñadas con el fin de detectar las falencias que presentaba la herramienta, con el fin de corregirlas posteriormente. Las pruebas aplicadas fueron "la prueba piloto" y "la prueba de campo", éstas se realizaron en la Universidad Pedagógica y Tecnológica de Colombia, seccional Duitama, en el programa de Licenciatura en Educación Industrial. A continuación se describen las pruebas y los resultados obtenidos. 


\section{Prueba piloto}

Esta se llevó a cabo con un grupo de 3 expertos, 2 en la temática de instalaciones eléctricas, y 1 experto en MECs. Se les presentó el material educativo para después realizar una entrevista que pretendía evaluar el material en aspectos como la temática contenida y su correcta organización y presentación, la estructura, los fondos, las imágenes, los videos, así como la administración del aprendizaje.

\section{Prueba de campo}

Una vez se realizó el primer ajuste a la herramienta, producto de los resultados de la prueba piloto, se procedió a aplicar la prueba de campo. Esta prueba se realizó con un grupo de treinta estudiantes, conformado por cinco estudiantes que ya habían cursado la asignatura, veinte estudiantes que la estaban cursando y cinco estudiantes novatos. La opinión de los estudiantes se recogió en un sondeo cuyas principales respuestas se presentan en la tabla 1.

\begin{tabular}{|c|c|c|c|c|c|}
\hline \multirow{2}{*}{ Preguntas } & \multirow{2}{*}{ Variables } & \multicolumn{3}{|c|}{ Respuesta } & \multirow{2}{*}{$\%$ Total } \\
\hline & & 20 E.C & $5 \mathrm{C}$. & $5 \mathrm{~N}$. & \\
\hline \multirow{2}{*}{$\begin{array}{l}\text { ¿Cree que los temas que se presentan en el MEC son } \\
\text { los adecuados? }\end{array}$} & $\mathrm{Si}$ & 19 & 5 & 4 & 93,3 \\
\hline & No & 1 & 0 & 1 & 6,6 \\
\hline \multirow{2}{*}{$\begin{array}{l}\text { ¿Cree que las imágenes y videos ayudaran a } \\
\text { mejorar el proceso enseñanza-aprendizaje? }\end{array}$} & $\mathrm{Si}$ & 20 & 4 & 3 & 90 \\
\hline & No & 0 & 1 & 2 & 10 \\
\hline \multirow{2}{*}{$\begin{array}{l}\text { ¿Esta de acuerdo que el MEC contenga música de } \\
\text { fondo? }\end{array}$} & $\mathrm{Si}$ & 6 & 1 & 5 & 40 \\
\hline & No & 14 & 4 & 0 & 60 \\
\hline \multirow{2}{*}{$\begin{array}{l}\text { ¿Esta de acuerdo con los colores, letras y fondos } \\
\text { aplicados en este material? }\end{array}$} & $\mathrm{Si}$ & 17 & 4 & 3 & 80 \\
\hline & No & 3 & 1 & 2 & 20 \\
\hline \multirow{2}{*}{$\begin{array}{l}\text { ¿Cree que esta herramienta deberia llevar una } \\
\text { evaluación de las tematicas estudiadas? }\end{array}$} & $\mathrm{Si}$ & 20 & 5 & 3 & 93,3 \\
\hline & No & 0 & 0 & 2 & 6,6 \\
\hline \multirow{2}{*}{$\begin{array}{l}\text { ¿Cree que la implementación de la plataforma } \\
\text { facilitaria la comunicación estudiante-profesor? }\end{array}$} & $\mathrm{Si}$ & 20 & 5 & 5 & \multirow{2}{*}{100} \\
\hline & No & 0 & 0 & 0 & \\
\hline \multirow{2}{*}{$\begin{array}{l}\text { ¿Esta de acuerdo que las actividades se desarrollen } \\
\text { en un tiempo limite? }\end{array}$} & $\mathrm{Si}$ & 19 & 5 & 4 & 93,6 \\
\hline & No & 1 & 0 & 1 & 6,6 \\
\hline
\end{tabular}

E.C = Estudiantes en curso $\mathbf{C}=$ Estudiantes esperimentados $\mathbf{N}=$ Estudiantes novatos

Tabla 1. Resultados prueba de campo.

\section{Resultados}

\section{Prueba piloto}

El análisis de esta prueba dio a conocer falencias que tenían que ver con:

- Temática: eliminación de algunas temáticas incluidas inicialmente, inclusión de las tablas utilizadas para la realización de cálculos.
- Presentación: usar imágenes para el fondo de los diferentes pantallazos que debían tener relación con la temática tratada, por ejemplo, transformadores, redes eléctricas, etc., además se recomendó incluir videos.

- Prueba de campo 
Dentro de los hallazgos más relevantes que se obtuvieron después de la aplicación de esta prueba están:

- La herramienta educativa tuvo buena aceptación, pues el 93\% de los estudiantes cree que facilita el estudio del área de instalaciones eléctricas.

- Todos los encuestados consideran que la implementación de la plataforma es buena para mejorar la comunicación entre el estudiante y el profesor.

. El 93\% estuvo de acuerdo con que se evaluaran las temáticas estudiadas en el MEC y que las actividades tuvieran un tiempo límite para su presentación.

. Los estudiantes expertos, aquellos que ya habían cursado la asignatura, mostraron gran aceptación por la herramienta y estuvieron de acuerdo con

\section{Conclusiones}

Dada la gran aceptación que tuvo la herramienta educativa, ésta se convierte en una excelente opción didáctica que permite acercar, de una manera amena y capaz de posibilitar el desarrollo de procesos de enseñanza-aprendizaje más eficientes, a los estudiantes con su objeto de estudio.

La evaluación es un elemento fundamental en el proceso de enseñanzaaprendizaje. En este caso, la evaluación y sus actividades complementarias se realizan alrededor de la plataforma, permitiendo que el estudiante utilice el MEC sin tener que enfrentar la evaluación hasta el momento que se considere preparado.

En el diseño y elaboración de materiales educativos computarizados se debe hacer uso del mayor número de herramientas multimedia, (videos, imágenes, animaciones, música, etc.) a fin de brindar al usuario diferentes opciones que su utilización permitirá mejorar el proceso enseñanza-aprendizaje en el área de instalaciones eléctricas, ya que el material contiene la información pertinente y actualizada para el desarrollo de la temática a la vez que presenta la información de una forma didáctica y agradable para los usuarios.

- El 90\% está de acuerdo con que las imágenes y los videos facilitan la aprehensión de los conocimientos.

- Sólo al 40\% de la población le gusta la música de fondo mientras explora el MEC, se optó por dejar la música de fondo como algo opcional.

- Aunque sólo el $20 \%$ sugirió cambios para mejorar la visibilidad del entorno, ésto fue suficiente para realizar las modificaciones sugeridas.

que faciliten la aprehensión de los conocimientos de una manera más fácil.

Para el desarrollo de esta herramienta se trabajó de manera sinérgica con un grupo de personas que estuvieron involucradas, desde el análisis de la necesidad de la herramienta, hasta la aplicación de las diferentes pruebas y corrección de falencias detectadas. Esto permitió tener diferentes puntos de vista que enriquecieron el desarrollo de la herramienta.

Cabe decir que si bien es cierto que la herramienta aquí descrita es una gran ayuda para los usuarios, en ningún momento se pretende reducir la importancia del docente como orientador en el proceso de apropiación del conocimiento por parte de los estudiantes.

Estos primeros resultados nos parecen satisfactorios y nos animan a seguir avanzando en esta línea de trabajo, diseñando nuevas ayudas que permitan facilitar la labor docente. 


\section{Referencias bibliográficas}

Alanís, A. (2000). El niño y la ciencia: el contacto necesario con el entorno sociocultural, Contexto Educativo, 14. Extraído desde http://www. contexto-educativo.com.ar/2000/ nota-05.htm.

Amaya, T. (2008). Material Educativo Computarizado (MEC) Para facilitar el proceso enseñanza-aprendizaje en las instalaciones eléctricas, tesis de pregrado, Universidad Pedagógica y Tecnología de Colombia, Facultad seccional Duitama, Licenciatura en Educación Industrial.

Bonza, E. F.; Fernández, F. H. y Duarte, J. E. (2008). Estudio de la energía y medio ambiente: una propuesta didáctica computarizada. Revista Tecné, Epistemé y Didaxis. Vol. 20.

De Corte, E. (1996). Aprendizaje apoyado en el computador: una perspectiva a partir de la investigación acerca del aprendizaje y la instrucción. En Memorias del III Congreso Iberoamericano de Informática Educativa. Barranquilla, Colombia: Servicio Nacional de Aprendizaje.

Flower, L. (2004). Manual de instalaciones eléctricas domiciliarias, Santafé de Bogotá: Schneider Electric.

Galvis, A. H. (1994). Ingeniería del software educativo. Bogotá: Uniandes.

Gonzáles, B. (2003). Diseño y construcción de prototipo didáctico para la enseñanza del campo electromagnético en niños, tesis de pregrado, Universidad Pedagógica y Tecnología de Colombia, seccional Duitama, Licenciatura en Educación Industrial.
Koschmann, T. (1996). CSCL: Theory and Practice of an Emerging Paradigm, Mahwah, N.J.: Lawrence Erlbaum Ass.

Lajoie, S. (1993). Computer Environments as Cognitive Tools for Enhancing Learning, en Lajoie, S. P. \& Derry, S. J. (eds.) Computers as Cognitive Tools (pp. 261-288). Hillsdale, N.J.: L. Erlbaum Ass.

Lamadrid, J. (1999). Enseñanza tecnológica: ¿Tecnicismo sin socialización? Contexto Educativo, 1. Extraido desde: http://www.contexto-educativo.com. ar/1999/11/nota-3.htm.

Lara, D., Lino, A., Ling, F. y Méndez, B. (2007). Tecnologías de información y comunicación. Extraido desde http:// www.monografias.com/trabajos37/ tecnologias-comunicacion/tecnologias-comunicacion.shtml

López, G. y Morcillo, J. (2007). Las TIC's en la enseñanza de la Biología en la educación secundaria: los laboratorios virtuales, Revista Electrónica de Enseñanza de las Ciencias 6 (3), 562-576.

Martínez, R., Montero, Y. y Pedrosa, M. (2005). La integración de la computadora a un ambiente de enseñanza aprendizaje. Revista Ibero Americana de Educación, 1(35).

Rosario, J. (2006). TIC: Su uso como Herramienta para el Fortalecimiento y el Desarrollo de la Educación Virtual. Observatorio para la CiberSociedad. Extraido desde http://www. cibersociedad.net/archivo/articulo. php?art=221. 